Uniwersytet w Białymstoku

Wydział Filologiczny

Instytut Filologii Wschodniosłowiańskiej

tel. +48857457450

e-mail: rszymula@interia.pl

ORCID ID: https://orcid.org/0000-0002-4879-4554

\title{
Средства воздействия на аудиторию в инаугурационных речах российских президентов
}

Ключевые слова: политический дискурс, инаугурационная речь, президент.

Главной целью политических партий и политиков является, несомненно, борьба за власть и ее удержание. С этой целью связано стремление завоевать и удержать симпатии граждан, получить их доверие и поддержку. Задачей политической борьбы является, между прочим, сформирование в сознании избирателей убеждений, соответствующих интересам конкретных политических субъектов, однако так, чтобы избиратели воспринимали их как соответствующие своим интересам. Чтобы этого достигнуть, политики используют разные средства: выбор темы выступления (социальные проблемы, важные для граждан), критика своих оппонентов (особенно в предвыборное время), риторические стратегии (аргументативные стратегии - обращение к логике; манипулятивные стратегии - обращение к чувствам и эмоциям). Данные приемы нацелены на оказание воздействия на граждан-избирателей с целью получения их поддержки. Хотя они особенно важны для предвыборного дискурса (их задача - побудить избирателей к желаемому действию, т.е. проголосовать за данного политика в ближайших выборах), однако, они характерны также для других типов политического дискурса (подготовка к следующей предвыборной кампании). 
Материалом для данного исследования послужили инаугурационные речи новоизбранных российских президентов [http://kremlin.ru]. Этот дискурсивный жанр сформировался в США, в России инаугурация президента проводилась только несколько раз. Исследователи подчеркивают высокую степень ритуальности данного жанра, преобладание в нем фатики над информативностью [Шейгал 2000, 69]. Характерными чертами инаугурационного выступления президента являются: сосредоточение внимания на настоящем при одновременном объединении на его фоне прошлого и будущего; представление аудитории как единого народа; подчеркивание традиционных для нации ценностей; ознакомление слушающих с политическими принципами, которыми будет руководствоваться новый президент [Campbell, Jamieson 1981, 122].

Говоря о речевой манипуляции, следует рассмотреть две категории понятий: речевые стратегии и речевые тактики. О. С. Иссерс определяет коммуникативную стратегию следующим образом: «комплекс речевых действий, направленных на достижение коммуникативных целей» [Иссерс 2003, 54]. О. Л. Михалева под коммуникативной стратегией понимает план оптимальной реализации коммуникативных намерений, учитывающий объективные и субъективные факторы и условия, в которых протекает акт коммуникации и которые обусловливают не только внешнюю и внутреннюю структуру текста, но также использование определенных языковых средств [Михалева 2009, 45]. В свою очередь коммуникативная тактика, по мнению А. П. Сковородникова, - это конкретный речевой ход (шаг, поворот, этап) в процессе реализации речевой стратегии [Сковородников 2004, 7].

Следует обратить также внимание на понятия аргументативных и манипулятивных стратегий. А. Н. Баранов определяет аргументацию как комплекс вербально реализованных когнитивных процедур обработки знания (дескрипция, метафоризация, экспликация, результаты интроспекции и др.), приводящих к изменению его онтологического статуса в модели мира адресата и реально или в перспективе влияющих на процесс принятия решений [Баранов 1990, 41]. Аргументация рассматривается как один из способов речевого воздействия на аудиторию. Говорящий пытается убедить слушающего (слушающих), влияя преимущественно на рациональное сознание человека, т. е. привести систему его оценок в соответствие со своей системой оценок. Е. Н. Зарецкая называет аргументацию воздействием на врожденную логику человека. Исследователь подчеркивает, что логическая аргументация является совокупностью тезисов и аргументов, так как это 
логический механизм доказательства и убеждения, и описывает механизм убеждения следующим образом: человек (Ч1) имеет систему взглядов $\left(\mathrm{C}^{1}\right)$, человек $\left(\mathrm{Ч}^{2}\right)$ имеет систему взглядов $\left(\mathrm{C}^{2}\right)$; чтобы свою систему взглядов (или взгляд на определенную проблему) перенести в сознание другого человека, следует набрать достаточное количество аргументов $\left(A_{1}, \ldots, A_{n}\right)$, которые бы показали несостоятельность точки зрения оппонента (вытеснение); после вытеснения из сознания оппонента его системы взглядов, человек (Ч¹) приступает к заполнению его своей системой убеждений посредством новой системы аргументов $\left(A_{n}^{1}, \ldots, A_{n}^{1}\right)$, т. е. происходит процесс замещения [Зарецкая 2001, 62-70]. Н. А. Безменова считает, однако, что аргументативные стратегии в риторике связаны не только с логикой, но и с эмоционально-психологической стороной высказывания [Безменова 1990, 23].

По мнению Е. Л. Доценко, манипулирование является видом психологического воздействия, искусное исполнение которого ведет к скрытому возбуждению у другого человека намерений, не совпадающих с его актуально существующими желаниями [Доценко 1997, 23]. В случае манипулятивных стратегий основной целью говорящего является достижение одностороннего выигрыша при помощи целенаправленного, скрытого внедрения в сознание адресата своих взглядов и установок, а также намеренного преобразования информации в высказывании (ее искажение, утаивание и т. п.) [Пономарев 2001, 16]. Воздействие на аудиторию направлено, прежде всего, на эмоции и чувства адресата. Л. А. Нефедова подчеркивает, что манипулятивные стратегии заметны на всех уровнях языка: на уровне слова (эмоционально окрашенная лексика), на уровне предложения (пустые фразы, стереотипы), на уровне текста (определенные риторические стратегии) [Нефедова 1997, 13].

О. Л. Михалева [Михалева 2009, 45] выделяет три стратегии речевой манипуляции, характерные для политического дискурса:

- стратегия на понижение;

- стратегия на повышение;

- стратегия театральности.

Стратегия на понижение направлена на формирование отрицательной оценки объекта у адресата при помощи понижения статуса данного объекта. Стратегия на повышение связана с созданием противоположного эффекта: с ее помощью говорящий добивается симпатии слушающего, создавая положительный образ (стремление говорящего максимально увеличить значимость собственного статуса). Стратегия театральности выделяется на основе, например, наличия в тексте экспрессивных речевых средств (театральный подход к ситуации пред- 
ставляет собой ее трактовку в качестве драмы, где люди стараются произвести друг на друга определенное впечатление). Каждая из перечисленных стратегий реализуется благодаря использованию определенного набора тактик. Стратегия на понижение реализуется через следующие тактики: тактика анализ-«минус» (основанное на фактах рассмотрение, разбор ситуации, предполагающий выражение отрицательного отношения к описываемому), тактика обвинения (приписывание кому-либо какой-либо вины, признание виновным в чем-либо, а также раскрытие чьих-либо неблаговидных действий, намерений, качеств), тактика безличного обвинения (обвинение, при котором не указываются виновники осуждаемых действий или поступков), тактика обличения (приведение с целью уличения фактов и аргументов, делающих явной виновность кого-либо), тактика оскорбления (нанесение обиды, сопровождаемое экспликацией эмоционального составляющего компонента вместо приведения доказательств), тактика угрозы (запугивание, обещание причинить адресату зло). Реализация стратегии на повышение осуществляется при помощи нескольких тактик: тактика анализ-«плюс» (основанное на фактах рассмотрение ситуации, предполагающее имплицитное выражение положительного отношения говорящего к описываемой ситуации), тактика презентации (представление кого-либо в привлекательном виде), тактика неявной самопрезентации (выраженное косвенно представление говорящим себя в выгодном свете), тактика отвода критики (приведение с целью доказательства невиновности аргументов и/или фактов, с помощью которых можно оправдать какие-либо действия и поступки), тактика самооправдания (отрицание негативных суждений об объекте критики и его причастности к тому, чему дается отрицательная оценка). Тактиками, которые служат реализации стратегии театральности, являются: тактика побуждения (призыв к какому-либо действию, принятию точки зрения), тактика кооперации (способ обращения к адресату, с помощью которого говорящий конструирует образ последнего, апеллируя к идеям и ценностям, носителем которых он - по мнению говорящего - является), тактика размежевания (выявление различий и несходства в позициях и мнениях), тактика информирования (приведение данных и фактов, не сопровождаемое выражением отношения говорящего), тактика обещания (обязательство сделать что-либо), тактика прогнозирования (предсказание о дальнейшем развитии чего-либо на основании интерпретации различных имеющихся данных), тактика предупреждения (предостережение, предваряющее извещение о возможных событиях, действиях, ситуациях и т. п.), тактика иронизирования (осуществление 
воздействия за счет контраста между сказанным и подразумеваемым), тактика провокации (подстрекательство кого-л. к таким действиям, которые могут повлечь за собой тяжелые для него последствия) [Михалева 2009, 45-67].

Перейдем к рассмотрению стратегий, которые используются в инаугурационных выступлениях российских президентов $(2000,2004,2008$, 2012). В исследуемом материале можем найти реализации двух речевых стратегий: стратегии на повышение и стратегии театральности.

Реализация стратегии на повышение осуществляется в анализируемых выступлениях с помощью тактики неявной самопрезентации. Ораторы пытаются показать себя в положительном свете, используя прием идентификации, т. е. уподобления оратора аудитории (мы-дискурс). Примером является использованное в инаугурационных речах приветствие Уважаемье граждане России! Дорогие друзья! Манипулятивное воздействие такого приема связано с его способностью обеспечивать контактную фазу общения [Шейгал 2000, 131]. Обращение друзья, несомненно, служит средством сближения с аудиторией и положительного расположения ей к говорящему. На внимание заслуживает также его употребление вместе с эмотивно окрашенным прилагательным дорогие. Другими способами создания в сознании слушателей ощущения, что президент - один из них, являются: употребление местоимения мы; употребление притяжательного местоимения наш; употребление лексем общий, совместный, сплоченный, единый, объединенный; употребление наречия вместе:

Вместе мы сможем изменить нашу жизнь к лучшему (Путин 2000).

Вместе мы сумели очень многое (Путин 2004).

Мы вместе прошли большой и сложный путь (Путин 2012).

Мы хотим, чтобы наша Россия была свободной, процветающей, богатой, сильной, цивилизованной страной (Путин 2000).

Рассчитываю, что мир и согласие в нашем общем доме будут и дальше укрепляться сотрудничеством разных конфессий (Медведев 2008).

Я рассчитываю на нашу совместную работу (Медведев 2008).

Мы добьемся наших целей, если будем единым, сплоченным народом, если будем дорожить нашим Отечеством (Путин 2012).

Я верю в силу наших общих целей и идеалов, в силу нашей решимости преобразить страну, в силу объединенных действий граждан, в наше общее стремление к свободе, к правде, к справедливости (Путин 2012).

Данные лексические средства используются также, чтобы призвать к единству народа, вызывая чувства солидарности, гордости, на- 
дежды (задача инаугурационной речи президента - объединить граждан) и чтобы не дифференцировать аудиторию (народ) по какому-либо признаку.

В проанализированных выступлениях создание ощущения общности оратора с аудиторией выполняет еще одну функцию: является средством расширения ответственности посредством перекладывания части ответственности с индивида на группу:

Я хорошо осознаю, какой груз ответственности ложится на мои плечи, и рассчитываю на нашу совместную работу (Медведев 2008).

Мир увидел возрожденную Россию, и это результат усилий нашего народа, общей напряженной работы, в которой есть личный вклад каждого (Путин 2012).

K приему идентификации можно также отнести ссылку на авторитет выдающихся личностей различных сфер деятельности, в случае политического дискурса особенно на политических деятелей. Этот риторический прием используется во всех инаугурационных речах российских президентов. Характерным элементом выступлений является обращение к предшествующему президенту (исключением является речь В. В. Путина, избранного на второй срок):

Первый президент России, Борис Николаевич Ельцин, покидая Кремль, сегодня вспомнил об этом, произнес слова, которые многим запомнились. Он сегодня повторил в этом зале: «Берегите Россию (Путин 2000). Я сердечно благодарю президента Владимира Владимировича Путина за его неизменную личную поддержку, которую я постоянно ощущал (Медведев 2008).

Я вижу в этом большую заслугу Дмитрия Анатольевича Медведева. [...] Впереди у него сложные и очень ответственные задачи. Я желаю ему успехов (Путин 2012).

Ссылка на предыдущих президентов - это подтверждение мирной преемственности власти. Она способствует переносу чувств и эмоций, связанных с данной личностью (эмоциональной оценки), на оратора новоизбранного президента. С этой целью используются также цитаты, например слова Б. Н. Ельцина, использованные в речи из 2000 г. как подтверждение того, что следующий президент будет продолжать политику своего предшественника и руководствоваться его принципами:

Он сегодня повторил в этом зале: «Берегите Россию». Именно в этом я вижу главную президентскую обязанность. Исполнение этого долга буду требовать и от своих соратников по работе, по службе. 
Другая стратегия, реализуемая в инаугурационных речах российских президентов, - это стратегия театральности. В ее рамках можно выделить тактику обещания:

Могу заверить вас, что в своих действиях буду руководствоваться исключительно государственными интересами (Путин 2000).

Обязанности президента хранить государство и верно служить народу и впредь будут для меня святы, и впредь будут для меня превыше всего (Путин 2004).

Буду работать активно, открыто и честно, сделаю все, что смогу, все, что в моих силах, чтобы оправдать надежды миллионов людей (Путин 2004).

В этой связи считаю своей важнейшей задачей дальнейшее развитие гражданских и экономических свобод, создание новых, самых широких возможностей для самореализации граждан - граждан, свободных и ответственных как за свой личный успех, так и за процветание всей страны (Медведев 2008).

Хотел бы заверить сегодня всех граждан страны, что буду работать с полной отдачей сил как президент и как человек, для которого Россия - это родной дом, родная земля (Медведев 2008).

Сделаю все, чтобы оправдать доверие миллионов наших граждан. Считаю смыслом всей своей жизни и своим долгом служение Отечеству, служение нашему народу, поддержка которого вдохновляет и помогает решать самые сложные и трудные задачи (Путин 2012).

Я верю в силу наших общих целей и идеалов, в силу нашей решимости преобразить страну (Путин 2012).

Для этой тактики характерно использование глаголов в форме будущего времени:

В своих действиях буду руководствоваться исключительно государственными интересами. Возможно, не удастся избежать ошибок, но что я могу обещать и обещаю, это то, что буду работать открыто и честно (Путин 2000).

Наши потомки будут гордиться теми страницами, которые мы с вами впишем в биографию великой России (Путин 2004).

Мы добьемся наших целей (Путин 2012).

Мы обязательно добьемся успеха (Путин 2012).

Мы хотим и будем жить в успешной России (Путин 2012).

Глаголы в форме будущего времени преобладают в последней части инаугурационных речей. Это связано с тем, что во всех речах ораторы переходят от прошлого через настоящее к будущему. 
Обещания со стороны президентов касаются различных сфер жизни (экономической, социальной и т. д.). Особое внимание уделяется таким ценностным доминантам общества, как материальное благополучие, образование, справедливость, равноправие, т. е. элементам, которые важны для всех жителей страны. Обещания, касающиеся именно этих элементов, с наибольшей вероятностью могут положительно расположить аудиторию к оратору:

Мы обязаны беречь достигнутое, хранить и развивать демократию (Путин 2000).

Теперь главная цель ближайшего четырехлетия - превратить уже накопленный нами потенциал в новую энергию развития. Достичь за счет этого принципиально лучшего качества жизни наших людей. Добиться реального, ощутимого роста их благосостояния (Путин 2004).

И мы будем делать все, чтобы каждый человек смог проявить свой талант и свои способности. Чтобы в стране развивалась реальная многопартийность, укреплялись личные свободы граждан. Чтобы люди в России могли получать хорошее образование, достойную социальную и медицинскую помощь. Чтобы они жили в достатке и могли завещать детям результаты своего собственного труда (Путин 2004).

В этой связи считаю своей важнейшей задачей дальнейшее развитие гражданских и экономических свобод, создание новых, самых широких возможностей для самореализации граждан (Медведев 2008).

Мы будем добиваться внедрения инновационных подходов во все сферы жизни, строить самые передовые производства, модернизировать промышленность и сельское хозяйство, создавать мощные стимулы для частных инвестиций и в целом стремиться к тому, чтобы Россия прочно утвердилась среди лидеров технологического и интеллектуального развития (Медведев 2008).

И я сделаю всё, чтобы безопасность граждан была не только гарантирована законом, но и реально обеспечена государством (Медведев 2008).

Безопасность, благополучие граждан страны всегда были и всегда останутся для меня превыше всего (Путин 2012).

Мы добьемся наших целей, (...) если будем дорожить нашим Отечеством, укреплять российскую демократию, конституционные права и свободы, расширять участие граждан в управлении страной (Путин 2012).

Мы хотим и будем жить в демократической стране, где у каждого есть свобода и простор для приложения таланта и труда, своих сил (Путин 2012). 
Другой тактикой, служащей реализации стратегии театральности, является тактика побуждения. В случае инаугурационных речей она осуществляется с помощью приема поиска поддержки у избирателей (граждан):

Я также рассчитываю найти в этом патриотическом деле помощь сограждан России, всех, кому дорога судьба нашего Отечества (Путин 2000).

Помощь и поддержка граждан Российской Федерации являются самой главной и самой надежной опорой в деятельности ее президента (Путин 2004).

Мы должны иметь широкую базу поддержки для того, чтобы продолжать преобразования в стране (Путин 2004).

Считаю смыслом всей своей жизни и своим долгом служение Отечеству, служение нашему народу, поддержка которого вдохновляет и помогает решать самые сложные и трудные задачи (Путин 2012).

Мир увидел возрожденную Россию, и это результат усилий нашего народа, общей напряженной работы, в которой есть личный вклад каждого (Путин 2012).

Реализация стратегии театральности осуществляется в инаугурационных выступлениях также при помощи тактики кооперации. Для этого ораторы используют прием апелляции к традиции. Президенты посредством обращения к прошлому подчеркивают, что для них важными являются традиционные ценности, извлеченные из прошлого нации:

Мы не должны забывать ничего, мы должны знать свою историю, знать ее такой, какая она есть, извлекать из нее уроки, всегда помнить о тех, кто создал Российское государство, отстаивал его достоинство, делал его великим, мощным, могучим государством (Путин 2000).

Мы с вами - наследники тысячелетней России. Родины выдающихся сынов и дочерей: тружеников, воинов, творцов. Они оставили нам с вами в наследство огромную, великую державу (Путин 2004).

Наше прошлое, безусловно, придает нам силы. Но даже самая славная история сама по себе не обеспечит нам лучшей жизни. Это величие должно быть подкреплено (Путин 2004).

Мы обязательно добьемся успеха, если будем опираться на прочный фундамент культурных и духовных традиций нашего многонационального народа, на нашу тысячелетнюю историю, на те ценности, которые всегда составляли нравственную основу нашей жизни, если каждый из нас будет жить по совести, с верой и любовью к Родине, к своим близким, заботиться о счастье своих детей и благополучии своих родителей (Путин 2012).

У России великая история и не менее великое будущее (Путин 2012). 
Особое место в этой тактике занимает ссылка на Кремль. В российской действительности Кремль является государственным символом, способным вызывать сильные эмоциональные реакции, концентрирующие в себе патриотическую гордость, память о прошлой славе, и одновременно обещающие будущее величие. Государственные символы всегда очень эмоциональны, они являются выражением общественных чувств, прежде всего патриотизма. Это эмоциональное воплощение нации, а также выразитель общенациональной идеи единства народа, его использование в речи помогает слушающим не только испытать, но и осознать патриотические чувства. Данный символ подчеркивает также церемониальный характер речи и ее торжественность:

Ради сегодняшнего торжественного события мы собрались сегодня здесь, в Кремле, в святом для нашего народа месте. Здесь в Кремле - сосредоточие нашей национальной памяти. Здесь, в стенах Кремля, веками вершилась история нашей страны (Путин 2000).

Материалом для данного исследования послужили инаугурационные речи Д. А. Медведева (2008) и В. В. Путина (2000, 2004, 2012). В России инаугурационное выступление является сравнительно новым дискурсивным типом. Его особенность состоит в том, что является действием не только речевым, но также политическим (произнесение речи - это акт формального введения нового президента в его должность). Целью данного исследования был анализ средств влияния на аудиторию, использованных в исследуемых инаугурационных речах. Проведенный анализ показал, что выступления вступающих в должность российских президентов реализуют определенные риторические стратегии и тактики, которые воздействуют на адресатов. К стратегиям речевой манипуляции, использованным президентами, принадлежат стратегия на повышение и стратегия театральности. Они pеализованы посредством определенных тактик. Тактикой неявной самопрезентации ораторы пользуются, чтобы создать ощущение общности со слушающими (мы-дискурс), а также (в случае ссылки на предыдущего президента), чтобы перенести на оратора эмоциональную оценку, связанную с цитированной личностью. Тактика обещания служит средством убеждения аудитории в том, что президент готов работать для блага граждан и успешно вести страну в светлое будущее. Благодаря тактике побуждения в сознании слушающих может создаваться впечатление, что они являются важными, что от них много зависит, что успех страны зависит именно от их усилий. В случае тактики кооперации ссылки на историю способствуют формированию у аудито- 
рии чувства гордости, пробуждению патриотизма, служат усилению пафоса речи. Все перечисленные тактики составляют своего рода саморекламу нового президента. Ораторы пытаются сформировать свой собственный положительный имидж. Положительному расположению аудитории к говорящему служит также выбор важных для граждан тем (государственная безопасность, благосостояние россиян, свобода и демократия и т. д.), что является подтверждением того, что политический курс президента является правильным.

Стоит подчеркнуть, что в инаугурационных выступлениях не используются тактики, характерные для типичного аргументативного воздействия на аудиторию (обращение к логике, а не к чувствам), такие как, например, тактика приведения примера. В случае аргументативных тактик процесс влияния на сознание аудитории происходит с учетом апелляции к рациональной сфере адресатов (фактических данных, статистических данных). Риторические приемы, использованные в инаугурационных речах российских президентов, можно назвать эмоциональной манипуляцией, так как они воздействуют на слушающих при помощи риторических средств, придающих выступлению эмоциональный оттенок, обращаются к чувствам и эмоциям аудитории и воздействию на эмоционально-психологическую сторону слушателей, а не на их логику.

\section{Литература}

Baranov A.N., 1990, Argumentaciâ kak âzykovoj i kognitivnyj fenomen, [v:] Rečevoe vozdejstvie v sfere massovoj kommunikacii, Moskva, s. 40-52. [Баранов A.Н., 1990, Аргументация как языковой и когнитивный феномен, [в:] Речевое воздействие в сфере массовой коммуникачии, Москва, с. 40-52.]

Bezmenova N.A., 1990, Ritoričeskâ̂ model' rečevoj deâtel'nosti, [v:] Rečevoe vozdejstvie v sfere massovoj kommunikacii, Moskva, s. 15-27. [Безменова Н.А., 1990, Риторическая модель речевой деятельности, [в:] Речевое воздействие в сфере массовой коммуникации, Москва, с. 15-27.]

Zareckaâ E.N., 2001, Ritorika: Teoriâ i praktika rečevoj kommunikacii, Moskva. [Зарецкая Е.Н., 2001, Риторика: Теория и практика речевой коммуникации, Москва.]

Docenko E.L., 1997, Psihologiâ manipulâcii: fenomeny, mehanizmy i zaŝita, Moskva. [Доценко Е.Л., 1997, Психология манипуляиии: Феномень, механизмы и защита, Москва.]

Issers O.S., 2003, Kommunikativnye strategii i taktiki russkoj reči, Moskva. [Иcсерс О.С., 2003, Коммуникативнье стратегии и тактики русской речи, Москва.] 
Mihaleva O.L., 2009, Političeskij diskurs: Specifika manipulâtivnogo vozdejstviâ, Moskva. [Михалева О.Л., 2009, Политический дискурс: Специфика манипулятивного воздействия, Москва.]

Nefedova L.A., 1997, Leksičeskie sredstva manipulâtivnogo vozdejstviâ v povsednevnom obŝenii, diss. ... kand. filol. nauk, Moskva. [Нефедова Л.А., 1997, Лексические средства манипулятивного воздействия в повседневном общении, дисс. ... канд. филол. наук, Москва.]

Ponomarev S.V., 2001, Verbal'nye kommunikacii v sisteme pablik rilejšinz, avtoref. ... diss. kand. fil. nauk, Moskva. [Пономарев C.В., 2001, Вербальныее коммуникации в системе паблик рилейшинз, автореф. ... дисс. канд. филол. наук, Москва.]

Skovorodnikov A.P., 2004, O neobhodimosti razgraničeniâ ponâtij «ritoričeskij priem», «stilističeskâa figura», «rečevâ̂ taktika», «rečevoj žanr»v praktike terminologičeskoj leksykografii, [v:] Ritorika. Lingvistika: sb. st., Smolensk, Vyp. 5, s. 5-11. [Сковородников А.П., 2004, О необходимости разграничения понятий «риторический прием», «стилистическая фигура», «речевая тактика», "речевой жанр» в практике терминологической лексикографии, [в:] Риторика. Лингвистика: сб. ст., Смоленск, Вып. 5, c. $5-11$.

Šejgal E.I., 2000, Semiotika političeskogo diskursa, Volgograd. [Шейгал Е.И., 2000, Семиотика политического дискурса, Волгоград.]

Banasik A., 2002, Jak uwodza politycy? Język marketingu politycznego w kampanii wyborczej '97, Katowice 2002.

Campbell K. K., Jamieson K. H., 1986, Inaugurating the Presidency, [w:] Form, Genre and the Study of Political Discourse, Columbia (S. Car.), s. 203-225.

Kamińska-Szmaj I., 2004, Propaganda, perswazja, manipulacja - próba uporzadkowania pojęć, [w:] Manipulacja w języku, red. P. Krzyżanowski i P. Nowak, Lublin, s. 13-27.

http://www.kremlin.ru [27.03.2018]

\section{MEANS OF INFLUENCING THE AUDIENCE IN THE INAUGURAL SPEECHES OF THE RUSSIAN PRESIDENTS}

\section{S U M M A R Y}

The material for this study were the inaugural speeches of D. A. Medvedev (2008) and V. V. Putin $(2000,2004,2012)$. The subject of the study are manipulative tactics used in the analyzed speeches. Their task is to form an opinion of the addressees, control their behaviour on the basis of involuntary formation of motivation, influence on thoughts, but above all on the emotions of citizens. The collected material showed that in the inaugural speeches of incoming Russian presidents, manipulative tactics are used at the text level (certain rhetorical means). 